\title{
Ubiquitin in the peroxisomal protein import pathway
}

\section{Tânia Francisco', Tony A. Rodrigues' ${ }^{1}$, Manuel P. Pinto $^{2}$, Andreia F. Carvalho², Jorge E. Azevedo ${ }^{3}$, Cláudia P. Grou 4}

Originally published in Biochimie. 2014 Mar; 98: 29-35. Elsevier. DOI: 10.1016/j.biochi.2013.08.003.

${ }^{1}$ Organelle Biogenesis and Function Group, Instituto de Biologia Celular e Molecular (IBMC), Universidade do Porto, R. do Campo Alegre, 823, 4150-18o Porto, Portugal; Instituto de Ciências Biomédicas Abel Salazar (ICBAS), Universidade do Porto, R. de Jorge Viterbo Ferreira, 228, 4050313 Porto, Portugal.

${ }^{2}$ Organelle Biogenesis and Function Group, Instituto de Biologia Celular e Molecular (IBMC), Universidade do Porto, R. do Campo Alegre, 823, 4150-180 Porto, Portugal.

${ }^{3}$ Organelle Biogenesis and Function Group, Instituto de Biologia Celular e Molecular (IBMC), Universidade do Porto, R. do Campo Alegre, 823, 4150-180 Porto, Portugal; Instituto de Ciências Biomédicas Abel Salazar (ICBAS), Universidade do Porto, R. de Jorge Viterbo Ferreira, 228, 4050313 Porto, Portugal. Electronic address: jazevedo@ibmc.up.pt.

${ }^{4}$ Organelle Biogenesis and Function Group, Instituto de Biologia Celular e Molecular (IBMC), Universidade do Porto, R. do Campo Alegre, 823, 4150-18o Porto, Portugal. Electronic address: cpgrou@ibmc.up.pt.

\begin{abstract}
PEX 5 is the shuttling receptor for newly synthesized peroxisomal matrix proteins. Alone, or with the help of an adaptor protein, this receptor binds peroxisomal matrix proteins in the cytosol and transports them to the peroxisomal membrane docking/translocation module (DTM). The interaction between cargo-loaded PEX 5 and the DTM ultimately results in its insertion into the DTM with the concomitant translocation of the cargo protein across the organelle membrane. PEX 5 is not consumed in this event; rather it is dislocated back into the cytosol so that it can promote additional rounds of protein transportation. Remarkably, the data collected in recent years indicate that dislocation is preceded by monoubiquitination of $\mathrm{PEX}_{5}$ at a conserved cysteine residue. This mandatory modification is not the only type of ubiquitination occurring at the DTM. Indeed, several findings suggest that defective receptors jamming the DTM are polyubiquitinated and targeted to the proteasome for degradation.
\end{abstract}




\section{INTRODUCTION}

Covalent attachment of ubiquitin (Ub) to a protein substrate requires an enzymatic cascade comprising three components: 1) an ATP-dependent ubiquitin-activating enzyme (E1); 2) an ubiquitin-conjugating enzyme (E2); and 3 ) an ubiquitin ligase ( $\left.E_{3}\right)$. For many years this posttranslational modification was best known as a signal leading to protein degradation at the proteasome [1]. Presently, however, it is clear that ubiquitination is also used in a reversible manner to regulate almost all biological pathways in eukaryotic cells [2-4]. This reversibility is ensured by the action of deubiquitinating enzymes (DUBs), a group of proteases that specifically remove the ubiquitin moieties from the modified proteins [5]. The generalized use and complexity of ubiquitination/deubiquitination strategies in the spatiotemporal regulation of biological processes can be easily appreciated by considering just two properties of ubiquitin biology. The first is the overwhelming number of genes encoding proteins dedicated to ubiquitin conjugation/ deconjugation that can be found in any eukaryotic organism (mammals have 2 E1s, 40 E2s, more than 600 E3s and approximately 100 DUBs) [6]. The second is that ubiquitination can take many different forms. Indeed, proteins can be modified with a single ubiquitin (monoubiquitination), two or more ubiquitin molecules, each attached to a different amino acid residue (multi-ubiquitination), or with an ubiquitin chain (polyubiquitination). In the latter case, the complexity is further increased because different $E_{2} / E_{3}$ pairs can build polyubiquitin chains with different topologies. The final outcome of each of these modifications is not the same because the effectors that ultimately recognize and decode these ubiquitin signals are also different [7]. This review focuses on the mechanism of protein sorting into the peroxisome matrix, a biological pathway providing a remarkable example of how ubiquitination is used not just as part of a quality control process but also as one of its intrinsic steps.

\section{An overview on the peroxisomal import machinery (PIM)}

Peroxisomal matrix proteins are synthesized on cytosolic ribosomes and post-translationally targeted to the peroxisome via one of two peroxisome targeting signals (PTS) [8]. The majority of them possess a PTS type 1 (PTS1) at their $C$ termini, a conserved tripeptide, usually with the sequence S-K-L $[9,10]$. Some peroxisome matrix proteins contain instead a PTS2. This is an Nterminal degenerated nonapeptide with the sequence $(R / K)-(L / V / I)-X_{5}-(H / Q)-(L / A)$, which in higher eukaryotes is cleaved upon import [11e 14]. In mammals, plants and many other organisms both PTS 1 and PTS 2 proteins are transported to the peroxisome by PEX $_{5}$, the peroxisomal shuttling receptor [15-19]. PEX 5 is a monomeric 70- kDa protein rich in intrinsically disordered domains [2022]. The interaction of $P E X_{5}$ with PTS 1 proteins is mediated by the PTS 1 on one side and a PEX 5 domain containing seven tetratricopeptide repeats (TPRs) on the other, but other regions of the cargo protein and other domains of PEX 5 also contribute to the interaction [23-27]. The PTS2-PEX 5 interaction, on the other hand, requires the adaptor protein $\mathrm{PEX}_{7}[15,17-19]$. The situation in yeasts and fungi is slightly different because their PEX 5 proteins lack a PEX7-interacting domain. In these organisms, PTS2 proteins are instead transported to the peroxisome by a protein complex comprising $\mathrm{PEX}_{7}$ and a species-specific peroxin that displays structural/functional similarities to the $\mathrm{N}$-terminal half of mammalian PEX $5[12,28,29]$. These species-specific peroxins (i.e., PEX $18, \mathrm{PEX}_{20}$ and PEX 21 ; see Table 1 ) are here referred to as PEX 5 -related proteins. Following cargo recognition in the cytosol, $\mathrm{PEX}_{5}$ interacts with the docking/translocation module (DTM), a multisubunit protein complex of the peroxisomal membrane comprising the core components $\mathrm{PEX}_{2}, \mathrm{PEX} 10, \mathrm{PEX} 12$, 
PEX13 and PEX14 (see Table 1) [30-32]. This interaction ultimately results in the insertion of PEX 5 into the DTM with PEX5 adopting a transmembrane topology $[33,34]$. The presently available data suggest that cargo translocation across the peroxisomal membrane is coupled to the insertion of the receptor into the DTM ([35,36] and unpublished results). Remarkably, none of these steps requires ATP hydrolysis, a finding that led to the proposal that the driving force for the cargo translocation step resides in the strong, essentially irreversible, interactions that PEX 5 establishes with components of the DTM [37-40]. Upon release of its cargo, DTM-embedded PEX 5 has to be exported to the cytosol so that it can promote additional rounds of protein transportation. Many of the details of this process have been uncovered in recent years. First, $\mathrm{PEX}_{5}$ is monoubiquitinated in an unconventional manner $[41,42]$. Then, this monoubiquitinated PEX 5 species (Ub-PEX 5 ) is extracted from the DTM in an ATP-dependent manner by the receptor export module (REM) $[40,41,43]$. This is a protein complex comprising the two AAA ATPases, PEX 1 and PEX6, and their membrane anchor PEX26 (or PEX15 and APEMg in Saccharomyces cerevisiae and plants, respectively; see Table 1) [44-47]. Finally, the ubiquitin moiety is removed from Ub-PEX5 probably by a combination of enzymatic and non-enzymatic mechanisms thus resetting the protein transport system [48-50]. Monoubiquitination of $\mathrm{PEX}_{5}$ or $\mathrm{PEX}_{5}$-related peroxins is not the only type of ubiquitination occurring at the DTM. Indeed, a number of studies have revealed that these receptors are also targets of polyubiquitination, a modification that probably reflects the existence of a quality control system [51-54]. The properties of both types of ubiquitination occurring at the DTM are described below.

\section{Peroxisomes and the ubiquitin-proteasome system}

Although mammalian PEX2, a RING finger peroxin and a core component of the DTM, was one of the first proteins involved in peroxisome biogenesis to be identified [55-57], the link between RING proteins and E3s was not known at the time [58], and, therefore, the connection between peroxisome biogenesis and the ubiquitin pathway was not immediately perceived. The first data pointing to this connection came from the identification of a yeast peroxin, PEX4. Primary structure analysis of this protein revealed an obvious homology with ubiquitin E2s and, indeed, mutation of its catalytic cysteine was sufficient to block peroxisome biogenesis in yeast [59]. Further characterization of $\mathrm{PEX}_{4}$ revealed that this $\mathrm{E}_{2}$ is anchored to the peroxisomal membrane via PEX22, an intrinsic membrane protein. In the absence of PEX22, PEX 4 becomes unstable indicating that the two proteins comprise a functional/structural unit [6o]. Strikingly, all attempts to identify the mammalian PEX 4 and PEX 22 counterparts using either genomic or proteomic approaches failed [61e66] (but see Section 4). Interestingly, the steady-state levels of PEX 5 and PEX2O in Pichia pastoris strains lacking PEX 4 were found to be heavily decreased $[53,60,67]$, a phenomenon that could be reversed by the simultaneous deletion of any of a group of genes encoding components of the DTM [67]. In strains lacking components of the REM the steady-state levels of both receptors were also diminished $[53,67]$. Apparently, a blockade at late steps of the import pathway induces the degradation of the shuttling receptors. Although no such phenomenon is observed in $\mathrm{S}$. cerevisiae, it was shown that a fraction of PEX 5 found in mutant strains lacking PEX 4 , PEX 1 or PEX6 is ubiquitinated, a process involving the cytosolic E2S Ubc1, Ubc4 and Ubc5 $[51,52,54,60]$. Altogether these data led to the proposal that there is an ubiquitin-based quality control system acting on receptors at the DTM that can no longer return to the cytosol using the normal mechanism (see Fig. 1 and following section). 


\section{Ubiquitination as an intrinsic step of the peroxisomal import pathway}

The data described above implicated PEX4 as an important player of the PIM, but did not unveil its mechanistic role. Research on this issue turned out to reveal one of the most interesting aspects of the PIM. The first hints on the function of PEX 4 emerged from bio-informatic analyses proposing that the PIM and the Endoplasmic Reticulum-associated degradation (ERAD) machinery display structural/functional similarities $[68,69]$. In particular, those studies postulated that the role of PEX4 in the PIM should be similar to the one of Ubc1/Ubc6/Ubc7 in the ERAD system, namely, the ubiquitination of a membrane-associated substrate so that it can be recognized and dislocated into the cytosol by AAA ATPases. The substrate in the ERAD system is a misfolded protein en route to the proteasome whereas in the PIM the substrate should be DTM-embedded PEX 5 or PEX 5 -related proteins. Indeed, subsequent work using yeast and a mammalian peroxisomal in vitro import system provided the experimental evidence to support this hypothesis. Collectively, these studies showed that: 1) yeast $\mathrm{PEX}_{4}$ monoubiquitinates $\mathrm{PEX}_{5}$ at a conserved cysteine residue $[42] ; 2$ ) mammalian DTM-embedded PEX ${ }_{5}$ is also monoubiquitinated at the conserved cysteine [41]; and 3) monoubiquitination of yeast and mammalian PEX 5 at the DTM is a mandatory step for their subsequent export into the cytosol, a process catalyzed by the ATP-dependent REM $[41,43]$. These findings also provided the explanation for earlier reports showing that deletion of a small $\mathrm{N}$ terminal domain containing the conserved cysteine residue of human PEX 5 , or mutation of this cysteine in both $\mathrm{P}$. pastoris $\mathrm{PEX} 20$ and human $\mathrm{PEX}_{5}$, resulted in proteins that could still enter the DTM but that were no longer substrates for the REM $[38,70,71]$. Recently, direct evidence showing that $\mathrm{S}$. cerevisiae $\mathrm{PEX} 18$ and $\mathrm{P}$. pastoris $\mathrm{PEX} 20$ are indeed modified by this type of unconventional ubiquitination was provided $[72,73]$. The finding that mammalian and yeast PEX 5 are both monoubiquitinated at the DTM was unexpected at the time because, as stated above, mammals lack PEX 4 and PEX22. On one hand, it was now obvious that the PIM of yeasts and mammals operate using similar principles, despite significant differences in their protein composition (see Table 1) [30-32]. On the other hand, it was evident that we were still missing components of the mammalian PIM. Using a peroxisome-dependent PEX 5 monoubiquitination assay it was found that the long-sought mammalian E2 activity cofractionated with cytosolic proteins [74]. Actually, a simple low speed centrifugation of a post-nuclear supernatant was sufficient to separate the E2 activity involved in this unconventional ubiquitination from peroxisomes, indicating that contrary to the situation in yeasts/fungi and probably also plants $[59,60,66,75]$, the mammalian E2 enzyme is not stably bound to the peroxisomal membrane. Standard protein purification procedures followed by mass spectrometry led to its identification. Interestingly, not one but rather three different E2S were found in that study. These are the almost identical E2 $\mathrm{D}_{1}, \mathrm{E}_{2} \mathrm{D}_{2}$ and $\mathrm{E}_{2} \mathrm{D}_{3}$ (also known as $\mathrm{UbcH}_{5}$ a, b and $\mathrm{c}$ in humans), a group of multipurpose cytosolic E2 enzymes involved in numerous biological pathways $[76,77]$. Three of the five core components of the DTM have $\mathrm{Zn}^{2+}$-binding domains. These are PEX $2, P_{10}$ and PEX12, a trio of proteins generally referred to as the "RING peroxins". However, it must be noted that the typical sequence motif that characterize RING domains is found only in PEX10 from all organisms. Most PEX 2 proteins also have this motif but there are some notorious exceptions (e.g., S. cerevisiae) $[78,79]$, whereas all PEX12 proteins are completely atypical, lacking several of the eight conserved $\mathrm{Zn}^{2+}$-binding residues found in RING domains. Indeed, the corresponding domain of S. cerevisiae PEX12 was recently shown to bind only one $\mathrm{Zn}^{2+}$ [78]. Considering that RING domains define the largst class of $\mathrm{E}_{3}$ ubiquitin ligases, it was evident from the very first findings on receptor ubiquitination that the RING peroxins must have a role in these modifications. In agreement with this idea, it has been reported that the $\mathrm{Zn}^{2+}$-binding domains alone have $\mathrm{E}_{3}$ activity in in vitro ubiquitination assays [79-81]. Interestingly, although the 
$\mathrm{Zn}^{2+}$-binding domains of all these proteins are exposed into the cytosol, monoubiquitination of PEX 5 and PEX 5 - related proteins occurs only when these receptors are already embedded in the DTM. On the other hand, insertion of PEX 5 into the DTM is not dependent on these peroxins $[16,30,67,82]$. Thus, the DTM resembles multi-subunit $E_{3}$ ligases, in which substrates are recruited not by the RING proteins themselves but rather by other subunits of the protein complex (see Ref. [39]). Which of the three RING peroxins of the DTM (if any alone) mediates the unconventional ubiquitination of PEX 5 remains unknown. We note that some attempts to address this issue using recombinant peroxin $\mathrm{Zn}^{2+}$-binding domains and $\mathrm{PEX}_{5}$ in in vitro ubiquitination assays have been reported [81]. However, no evidence for bona fide monoubiquitinated PEX 5 was found so far. An interesting property of the RING peroxins is that the absence of any of these proteins leads to the instability of the other two $[30,83,84]$. This phenomenon suggests that the three proteins comprise a structural unit within the DTM, as is in fact supported by protein purification studies in yeast [30]. Interestingly, recent data suggest that the three RING peroxins may also display a functional interdependence. Indeed, disruption of the RING domain of any of these peroxins leads to a complete loss of both mono- and polyubiquitination of P. pastoris PEX20 [73]. These important findings suggest that all RING peroxins en bloc are required for both types of receptor ubiquitination and raise the appealing possibility that the RING peroxins may be simply modules of a single multi- $\mathrm{Zn}^{2+}$-binding domain ubiquitin ligase. An example of this type of architecture is provided by the RING-in-between-RING(IBR)-RING (RBR) family of ubiquitin ligases, a class of E3S that use a Homologous to E6-AP C terminus (HECT) E3-like mechanism to ubiquitinate a substrate. The catalytic regions of RBR E3s comprise three closely spaced domains: a canonical RING domain (RING1) which serves as the binding platform for the ubiquitin-loaded $\mathrm{E}_{2}$; a $\mathrm{Zn}^{2+}$-binding domain (the so-called IBR) which probably has a structural/regulatory role; and another $\mathrm{Zn}^{2+}$-binding domain, originally named the RING2 domain, which contains the catalytic cysteine [85]. RBR E3 ligases, therefore, provide a remarkable example of how multiple $\mathrm{Zn}^{2+}$-binding domains can be structurally and functionally organized to perform a single function. Considering the P. pastoris data referred to above, it is tempting to speculate that a similar, although not necessarily identical, situation will be found for the RING peroxins.

\section{Receptor dislocation and deubiquitination}

According to current models (see Fig. 1 and Refs. [39,86e88]), there are at least four steps occurring during the transient passage of PEX 5 through the peroxisomal DTM before its export into the cytosol: 1 ) docking; 2 ) insertion into the DTM/cargo protein translocation; 3 ) cargo release into the peroxisome matrix; and 4 ) monoubiquitination. In principle, monoubiquitination of PEX 5 could coincide in time with any of the other three steps and even modulate/trigger one of them as was in fact previously proposed for the cargo release step [42]. However, several findings obtained with an in vitro peroxisomal import system suggest that this is not the case. Indeed, in the absence of an operating ubiquitin-conjugation cascade $\mathrm{PEX}_{5}$ can still enter the DTM where it acquires the expected transmembrane topology $[40,41]$; the same is true for PEX ${ }_{5}$ mutant proteins lacking the conserved cysteine residue $[41,70]$. Likewise, PEX 5-mediated peroxisomal import of pre-thiolase, a PTS2 protein, and its processing in the peroxisomal matrix are also not affected when the ubiquitinconjugating cascade is blocked, a conclusion that we have recently extended also to PTS1 proteins ([35] and unpublished observations). Thus, docking, insertion and cargo release do not depend on monoubiquitination of PEX 5 . These observations strongly suggest that monoubiquitination of PEX 5 is required for nothing else other than its export into the cytosol, a step catalyzed by the AAA

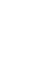


ATPases of the REM, PEX 1 and PEX6. The mechanistic details of how monoubiquitinated PEX 5 and PEX 5 -related proteins are recognized by the REM are not entirely understood. In principle, the REM could interact directly with DTM-embedded monoubiquitinated receptors. Alternatively, the recognition event might be mediated by an ubiquitin-binding adaptor protein. Some data supporting this last possibility was recently reported [89]. Using an in vitro import/export system, the authors noticed that export of peroxisomal PEX 5 could be stimulated by adding back cytosolic proteins to the organelle fraction. Purification of this cytosolic activity led to the identification of $A \mathrm{WP}_{1}$, an ubiquitin-binding protein previously shown to interact with a member of the protein kinase C family [90] and to be a regulator of the NF-kB signaling pathway [91,92]. Protein-protein interaction studies led the authors to conclude that $A W P_{1}$ mediates the interaction of Ub-PEX 5 with the REM thus explaining its stimulatory effect on PEX 5 export. Dislocation of DTM-embedded Ub-PEX 5 back into the cytosol is followed by its deubiquitination. This step is probably very fast in vivo because dithiothreitol-sensitive Ub-PEX 5 species can only be detected in organelle fractions $[42,49,93]$. The DUBs acting on Ub-PEX 5 have been recently identified in both yeast (UBP15) and mammals (USP9X) $[48,50]$. Interestingly, knock-out and knockdown of UBP15 and USP9X genes, respectively, do not lead to an accumulation of Ub-PEX 5 in the cytosol, as would be expected if these enzymes were the only mean to remove ubiquitin from PEX 5 . Clearly, there are alternative ways to deubiquitinate $\mathrm{PEX}_{5}$, which may or may not include other less active/redundant DUBs. Indeed, as proposed recently deubiquitination of PEX 5 does not have to necessarily involve a DUB [49]. This is due to the fact that the thioester bond linking ubiquitin to PEX 5 is quite labile in the presence of physiologically relevant concentrations of glutathione, displaying a half-life of just 2.3 min. Interestingly, DTM-embedded Ub-PEX 5 is resistant to this trans-thiolation reaction suggesting that such non-enzymatic deubiquitinating mechanism would not create a futile ubiquitination/deubiquitination cycle at the DTM. Deubiquitination of PEX 5 completes the PEX 5 mediated protein import cycle.

\section{Concluding Remarks}

Our understanding on the PEX5-mediated protein import pathway has increased dramatically in the last decade. The field has clearly moved into the functional/structural characterization of this machinery and we now have at least some ideas, as faint as they may be, on the role played by all components of the PIM. The challenge now is to understand its mechanistic details. Particularly puzzling in the PIM/ubiquitin topic is the fact that monoubiquitination of PEX 5 and PEX 5 -related receptors occurs at a cysteine residue. This would be the expected situation if these receptors were E3-like proteins such as the members of the HECT and RBR E3 family [94]. However, this is clearly not the case: substitution of the conserved cysteine by a lysine (the classical target of ubiquitination) results in a PEX5 protein displaying seemingly normal import/export activities both in in vitro and in vivo assays [49]. We do know that, in contrast to quality control polyubiquitination, unconventional ubiquitination of receptors occurs at each protein import cycle, meaning that each receptor molecule is probably subjected to hundreds/thousands of monoubiquitination/deubiquitination cycles during its life time. Maybe this property holds the answer to the cysteine enigma. The thiol group of a cysteine residue is a much stronger nucleophile and a better leaving group than the 3-amino group of a lysine. The first property means that ubiquitination at a cysteine residue has the potential to occur at a larger rate than the classical lysine-targeted ubiquitination. This would imply that by using unconventional monoubiquitination of its receptors the PIM could support larger protein import fluxes. We note that previous attempts 
aiming at detecting a difference between the monoubiquitination rates of PEX 5 and a PEX 5 protein possessing a cysteine-to-lysine substitution yielded negative results [49]. However, whether or not the PIM was working at its maximum capacity in the assays used in that work remains unknown, and thus a putatively rate-limiting step (i.e., monoubiquitination of the lysine-containing PEX 5 ) might have escaped detection. The fact that the thiol group of a cysteine residue is a good leaving group may also have an impact on the monoubiquitination/deubiquitination cycle of the receptors. Indeed, as discussed above, deubiquitination of these thioesters may be achieved simply by a nonenzymatic trans-acylation reaction of the bound ubiquitin to a physiological relevant nucleophile (e.g., glutathione). As hypothesized before, the existence of redundant deubiquitination mechanisms acting on these receptors might increase their half-lives [49]. Finally, it may be relevant to note that modification of the conserved cysteine of the receptors by any molecule other than ubiquitin would immediately block the DTM. Considering that cysteine residues can be modified in several manners (e.g., oxidized, and acylated), the conserved cysteine could also have a regulatory role functioning, for instance, as a sensor of oxidative stress. In this putative scenario, newly synthesized peroxisomal enzymes (e.g., catalase) would no longer be imported into the organelle and would remain in the cytosol $[49,95]$. We are still far from understanding how the RING peroxins work, but problems with this family of proteins are clearly not unique to the peroxisome biogenesis field. Naturally, in vitro ubiquitination assays using recombinant proteins may provide some of the answers we need, particularly if the substrate-binding subunit(s) of the peroxisomal $E_{3}$ is(are) included in the assays. The recent findings showing that all three RING peroxins are needed for both monoubiquitination and polyubiquitination of PEX 20 [73] should also be considered when performing this type of in vitro assays, because they raise the so-far unexpected possibility that the RING peroxins work, not alone, not in pairs, but rather as a trio of modules of a multi- $\mathrm{Zn}^{2+}$-binding domain $\mathrm{E}_{3}$ ligase. Clearly, there is still a long way to go before we understand the molecular details of receptor ubiquitination at the DTM.

\section{Acknowledgements}

This work was funded by FEDER funds through the Operational Competitiveness Programme e COMPETE and by National Funds through FCT e Fundação para a Ciência e a Tecnologia under the project FCOMP-01-0124-FEDER-019731 (PTDC/BIA-BCM/118577/ 2010). T.F., T.A.R., M.P.P. and C.P.G. are supported by Fundação para a Ciência e a Tecnologia, Programa Operacional Potencial Humano do QREN, and Fundo Social Europeu. A.F.C. is supported by Programa Ciência, funded by Programa Operacional Potencial Humano do OREN, Tipologia 4.2, Promoção do Emprego Científico, by Fundo Social Europeu and by National Funds from Ministério da Ciência, Tecnologia e Ensino Superior.

\section{REFERENCES}

[1] A. Hershko, A. Ciechanover, The ubiquitin system for protein degradation, Annu. Rev. Biochem. 61 (1992) 761-807.

[2] K. Haglund, I. Dikic, The role of ubiquitylation in receptor endocytosis and endosomal sorting, J. Cell Sci. 125 (2012) 265-275.

INSTITUTO DE INVESTIIGAÇÃO E INOVAÇÃO EM SAÚDE UNIVERSIDADE DO PORTO

Rua Alfredo Allen, 208 4200-135 Porto Portugal +351220408800 
[3] I. Hammond-Martel, H. Yu, B. Affar el, Roles of ubiquitin signaling in transcription regulation, Cell Signal. 24 (2012) 410-421.

[4] C.H. Ramaekers, B.G. Wouters, Regulatory functions of ubiquitin in diverse DNA damage responses, Curr. Mol. Med. 11 (2011) 152-169.

[5] F.E. Reyes-Turcu, K.H. Ventii, K.D. Wilkinson, Regulation and cellular roles of ubiquitin-specific deubiquitinating enzymes, Annu. Rev. Biochem. 78 (2009) 363-397.

[6] A.P. Hutchins, S. Liu, D. Diez, D. Miranda-Saavedra, The repertoires of ubiquitinating and deubiquitinating enzymes in eukaryotic genomes, Mol. Biol. Evol. 30 (2013) 1172-1187.

[7] D. Komander, M. Rape, The ubiquitin code, Annu. Rev. Biochem. 81 (2012) 203-229.

[8] P.E. Purdue, P.B. Lazarow, Peroxisome biogenesis, Annu. Rev. Cell Dev. Biol. 17 (2001) 701-752.

[9] C. Brocard, A. Hartig, Peroxisome targeting signal 1: is it really a simple tripeptide? Biochim. Biophys. Acta 1763 (2006) 1565-1573.

[10] S.J. Gould, G.A. Keller, N. Hosken, J. Wilkinson, S. Subramani, A conserved tripeptide sorts proteins to peroxisomes, J. Cell Biol. 108 (1989) 1657-1664.

[11] M. Kunze, G. Neuberger, S. Maurer-Stroh, J. Ma, T. Eck, N. Braverman, J.A. Schmid, F. Eisenhaber, J. Berger, Structural requirements for interaction of peroxisomal targeting signal 2 and its receptor PEX7, J. Biol. Chem. 286 (2011) 45048-45062.

[12] P.B. Lazarow, The import receptor Pex7p and the PTS2 targeting sequence, Biochim. Biophys. Acta 1763 (2006) 1599-1604.

[13] B.W. Swinkels, S.J. Gould, A.G. Bodnar, R.A. Rachubinski, S. Subramani, A novel, cleavable peroxisomal targeting signal at the amino-terminus of the rat 3 -ketoacyl-CoA thiolase, EMBO J. 10 (1991) 3255-3262.

[14] S. Reumann, Specification of the peroxisome targeting signals type 1 and type 2 of plant peroxisomes by bioinformatics analyses, Plant Physiol. 135 (2004) 783-800.

[15] N. Braverman, G. Dodt, S.J. Gould, D. Valle, An isoform of pex5p, the human PTS1 receptor, is required for the import of PTS2 proteins into peroxisomes, Hum. Mol. Genet. 7 (1998) 1195-1205.

[16] G. Dodt, S.J. Gould, Multiple PEX genes are required for proper subcellular distribution and stability of Pex5p, the PTS1 receptor: evidence that PTS1 protein import is mediated by a cycling receptor, J. Cell Biol. 135 (1996) 1763-1774.

[17] N. Galland, F. Demeure, V. Hannaert, E. Verplaetse, D. Vertommen, P. Van der Smissen, P.J. Courtoy, P.A. Michels, Characterization of the role of the receptors $\mathrm{PEX}_{5}$ and $\mathrm{PEX}_{7}$ in the import of proteins into glycosomes of Trypanosoma brucei, Biochim. Biophys. Acta 1773 (2007) 521-535. 
[18] H. Otera, K. Okumoto, K. Tateishi, Y. Ikoma, E. Matsuda, M. Nishimura, T. Tsukamoto, T. Osumi, K. Ohashi, O. Higuchi, Y. Fujiki, Peroxisome targeting signal type 1 (PTS1) receptor is involved in import of both PTS1 and PTS2: studies with PEX5-defective $\mathrm{CHO}_{5}$ cell mutants, Mol. Cell. Biol. 18 (1998) 388-399.

[19] A.W. Woodward, B. Bartel, The Arabidopsis peroxisomal targeting signal type 2 receptor PEX7 is necessary for peroxisome function and dependent on PEX 5 , Mol. Biol. Cell 16 (2005) 573-583.

[20] A.F. Carvalho, J. Costa-Rodrigues, I. Correia, J. Costa Pessoa, T.Q. Faria, C.L. Martins, M. Fransen, C. Sa-Miranda, J.E. Azevedo, The N-terminal half of the peroxisomal cycling receptor Pex5p is a natively unfolded domain, J. Mol. Biol. 356 (2006) 864-875.

[21] J. Costa-Rodrigues, A.F. Carvalho, M. Fransen, E. Hambruch, W. Schliebs, C. Sa-Miranda, J.E. Azevedo, Pex5p, the peroxisomal cycling receptor, is a monomeric non-globular protein, J. Biol. Chem. 280 (2005) 24404-24411.

[22] K. Shiozawa, P.V. Konarev, C. Neufeld, M. Wilmanns, D.I. Svergun, Solution structure of human Pex5.Pex14.PTS1 protein complexes obtained by small angle X-ray scattering, J. Biol. Chem. 284 (2009) 25334-25342.

[23] M.O. Freitas, T. Francisco, T.A. Rodrigues, I.S. Alencastre, M.P. Pinto, C.P. Grou, A.F. Carvalho, M. Fransen, C. Sa-Miranda, J.E. Azevedo, PEX 5 protein binds monomeric catalase blocking its tetramerization and releases it upon binding the N-terminal domain of PEX14, J. Biol. Chem. 286 (2011) 40509-40519.

[24] G.J. Gatto Jr., B.V. Geisbrecht, S.J. Gould, J.M. Berg, A proposed model for the PEX5peroxisomal targeting signal-1 recognition complex, Proteins 38 (2000) 241-246.

[25] A.T. Klein, M. van den Berg, G. Bottger, H.F. Tabak, B. Distel, Saccharomyces cerevisiae acylCoA oxidase follows a novel, non-PTS 1 , import pathway into peroxisomes that is dependent on Pex5p, J. Biol. Chem. 277 (2002) 25011-25019.

[26] Y. Oshima, A. Kamigaki, C. Nakamori, S. Mano, M. Hayashi, M. Nishimura, M. Esaka, Plant catalase is imported into peroxisomes by Pex5p but is distinct from typical PTS 1 import, Plant Cell Physiol. 49 (2008) 671-677.

[27] I.J. van der Klei, M. Veenhuis, PTS1-independent sorting of peroxisomal matrix proteins by Pex5p, Biochim. Biophys. Acta 1763 (2006) 1794-1800.

[28] G. Dodt, D. Warren, E. Becker, P. Rehling, S.J. Gould, Domain mapping of human PEX5 reveals functional and structural similarities to Saccharomyces cerevisiae Pex18p and Pex21p, J. Biol. Chem. 276 (2001) 41769-41781.

[29] W. Schliebs, W.H. Kunau, PTS2 co-receptors: diverse proteins with common features, Biochim. Biophys. Acta 1763 (2006) 1605-1612. 
[30] B. Agne, N.M. Meindl, K. Niederhoff, H. Einwachter, P. Rehling, A. Sickmann, H.E. Meyer, W. Girzalsky, W.H. Kunau, Pex8p: an intraperoxisomal organizer of the peroxisomal import machinery, Mol. Cell 11 (2003) 635-646.

[31] S. Oeljeklaus, B.S. Reinartz, J. Wolf, S. Wiese, J. Tonillo, K. Podwojski, K. Kuhlmann, C. Stephan, H.E. Meyer, W. Schliebs, C. Brocard, R. Erdmann, B. Warscheid, Identification of core components and transient interactors of the peroxisomal importomer by dual-track stable isotope labeling with amino acids in cell culture analysis, J. Proteome Res. 11 (2012) 2567-2580.

[32] C. Reguenga, M.E. Oliveira, A.M. Gouveia, C. Sa-Miranda, J.E. Azevedo, Characterization of the mammalian peroxisomal import machinery: Pex2p, Pex5p, Pex12p, and Pex14p are subunits of the same protein assembly, J. Biol. Chem. 276 (2001) 29935-29942.

[33] A.M. Gouveia, C.P. Guimaraes, M.E. Oliveira, C. Reguenga, C. Sa-Miranda, J.E. Azevedo, Characterization of the peroxisomal cycling receptor, Pex5p, using a cell-free in vitro import system, J. Biol. Chem. 278 (2003) 226-232.

[34] A.M. Gouveia, C. Reguenga, M.E. Oliveira, C. Sa-Miranda, J.E. Azevedo, Characterization of peroxisomal Pex5p from rat liver. Pex5 in the Pex5p-Pex14p membrane complex is a transmembrane protein, J. Biol. Chem. 275 (2000) 32444-32451.

[35] I.S. Alencastre, T.A. Rodrigues, C.P. Grou, M. Fransen, C. Sa-Miranda, J.E. Azevedo, Mapping the cargo protein membrane translocation step into the PEX 5 cycling pathway, J. Biol. Chem. 284 (2009) 27243-27251.

[36] A.M. Gouveia, C.P. Guimaraes, M.E. Oliveira, C. Sa-Miranda, J.E. Azevedo, Insertion of Pex5P into the peroxisomal membrane is cargo protein-dependent, J. Biol. Chem. 278 (2003) 4389-4392.

[37] J.E. Azevedo, J. Costa-Rodrigues, C.P. Guimaraes, M.E. Oliveira, C. Sa-Miranda, Protein translocation across the peroxisomal membrane, Cell Biochem. Biophys.41 (2004) 451-468.

[38] J. Costa-Rodrigues, A.F. Carvalho, A.M. Gouveia, M. Fransen, C. Sa-Miranda, J.E. Azevedo, The $\mathrm{N}$ terminus of the peroxisomal cycling receptor, Pex5p, is required for redirecting the peroxisomeassociated peroxin back to the cytosol, J. Biol. Chem. 279 (2004) 46573-46579.

[39] C.P. Grou, A.F. Carvalho, M.P. Pinto, I.S. Alencastre, T.A. Rodrigues, M.O. Freitas, T. Francisco, C. Sa-Miranda, J.E. Azevedo, The peroxisomal protein import machinery - a case report of transient ubiquitination with a new flavor, Cell. Mol. Life Sci. 66 (2009) 254-262.

[40] M.E. Oliveira, A.M. Gouveia, R.A. Pinto, C. Sa-Miranda, J.E. Azevedo, The energetics of Pex5pmediated peroxisomal protein import, J. Biol. Chem. 278 (2003) 39483-39488.

[41] A.F. Carvalho, M.P. Pinto, C.P. Grou, I.S. Alencastre, M. Fransen, C. Sa-Miranda, J.E. Azevedo, Ubiquitination of mammalian Pex5p, the peroxisomal import receptor, J. Biol. Chem. 282 (2007) 31267-31272. 
[42] C. Williams, M. van den Berg, R.R. Sprenger, B. Distel, A conserved cysteine is essential for Pex4p-dependent ubiquitination of the peroxisomal import receptor Pex5p, J. Biol. Chem. 282 (2007) 22534-22543.

[43] H.W. Platta, F. El Magraoui, D. Schlee, S. Grunau, W. Girzalsky, R. Erdmann, Ubiquitination of the peroxisomal import receptor Pex5p is required for its recycling, J. Cell Biol. 177 (2007) 197-204.

[44] I. Birschmann, A.K. Stroobants, M. van den Berg, A. Schafer, K. Rosenkranz, W.H. Kunau, H.F. Tabak, Pex15P of Saccharomyces cerevisiae provides a molecular basis for recruitment of the AAA peroxin Pex6p to peroxisomal membranes, Mol. Biol. Cell 14 (2003) 2226-2236.

[45] S. Goto, S. Mano, C. Nakamori, M. Nishimura, Arabidopsis ABERRANT PEROXISOME MORPHOLOGY9 is a peroxin that recruits the PEX1-PEX6 complex to peroxisomes, Plant Cell 23 (2011) 1573-1587.

[46] N. Miyata, Y. Fujiki, Shuttling mechanism of peroxisome targeting signal type 1 receptor Pex5: ATP-independent import and ATP-dependent export, Mol. Cell. Biol. 25 (2005) 10822-10832.

[47] H.W. Platta, S. Grunau, K. Rosenkranz, W. Girzalsky, R. Erdmann, Functional role of the AAA peroxins in dislocation of the cycling PTS1 receptor back to the cytosol, Nat. Cell Biol. 7 (2005) 817822.

[48] M.O. Debelyy, H.W. Platta, D. Saffian, A. Hensel, S. Thoms, H.E. Meyer, B. Warscheid, W. Girzalsky, R. Erdmann, Ubp15p, a ubiquitin hydrolase-associated with the peroxisomal export machinery, J. Biol. Chem. 286 (2011) 28223-28234.

[49] C.P. Grou, A.F. Carvalho, M.P. Pinto, S.J. Huybrechts, C. Sa-Miranda, M. Fransen, J.E. Azevedo, Properties of the ubiquitin-Pex5p thiol ester conjugate, J. Biol. Chem. 284 (2009) 10504-10513.

[50] C.P. Grou, T. Francisco, T.A. Rodrigues, M.O. Freitas, M.P. Pinto, A.F. Carvalho, P. Domingues, S.A. Wood, J.E. Rodriguez-Borges, C. Sa-Miranda, M. Fransen, J.E. Azevedo, Identification of ubiquitin-specific protease $9 \mathrm{X}(\mathrm{USPg} X)$ as a deubiquitinase acting on ubiquitin-peroxin 5 (PEX 5 ) thioester conjugate, J. Biol. Chem. 287 (2012) 12815-12827.

[51] J.A. Kiel, K. Emmrich, H.E. Meyer, W.H. Kunau, Ubiquitination of the peroxisomal targeting signal type 1 receptor, Pex5p, suggests the presence of a quality control mechanism during peroxisomal matrix protein import, J. Biol. Chem. 280 (2005) 1921-1930.

[52] A. Kragt, T. Voorn-Brouwer, M. van den Berg, B. Distel, The Saccharomyces cerevisiae peroxisomal import receptor Pex5p is monoubiquitinated in wild-type cells, J. Biol. Chem. 280 (2005) $7867-7874$.

[53] S. Leon, L. Zhang, W.H. McDonald, J. Yates 3rd, J.M. Cregg, S. Subramani, Dynamics of the peroxisomal import cycle of PpPexzop: ubiquitin-dependent localization and regulation, J. Cell Biol. 172 (2006) 67-78. 
[54] H.W. Platta, W. Girzalsky, R. Erdmann, Ubiquitination of the peroxisomal import receptor Pex5p, Biochem. J. 384 (2004) 37-45.

[55] R. Patarca, M.A. Fletcher, Ring finger in the peroxisome assembly factor-1, FEBS Lett. 312 (1992) 1-2.

[56] N. Shimozawa, T. Tsukamoto, Y. Suzuki, T. Orii, Y. Shirayoshi, T. Mori, Y. Fujiki, A human gene responsible for Zellweger syndrome that affects peroxisome assembly, Science 255 (1992) 11321134 .

[57] T. Tsukamoto, S. Miura, Y. Fujiki, Restoration by a $35 \mathrm{~K}$ membrane protein of peroxisome assembly in a peroxisome-deficient mammalian cell mutant, Nature 350 (1991) 77-81.

[58] C.A. Joazeiro, A.M. Weissman, RING finger proteins: mediators of ubiquitin ligase activity, Cell 102 (2000) 549-552.

[59] F.F. Wiebel, W.H. Kunau, The Pasz protein essential for peroxisome biogenesis is related to ubiquitin-conjugating enzymes, Nature 359 (1992) 73-76.

[6o] A. Koller, W.B. Snyder, K.N. Faber, T.J. Wenzel, L. Rangell, G.A. Keller, S. Subramani, Pex22p of Pichia pastoris, essential for peroxisomal matrix protein import, anchors the ubiquitinconjugating enzyme, Pex4p, on the peroxisomal membrane, J. Cell Biol. 146 (1999) 99-112.

[61] M. Islinger, G.H. Luers, K.W. Li, M. Loos, A. Volkl, Rat liver peroxisomes after fibrate treatment. A survey using quantitative mass spectrometry, J. Biol. Chem. 282 (2007) 23055-23069.

[62] J.A. Kiel, M. Veenhuis, I.J. van der Klei, PEX genes in fungal genomes: common, rare or redundant, Traffic 7 (2006) 1291-1303.

[63] M. Kikuchi, N. Hatano, S. Yokota, N. Shimozawa, T. Imanaka, H. Taniguchi, Proteomic analysis of rat liver peroxisome: presence of peroxisome-specific isozyme of Lon protease, J. Biol. Chem. 279 (2004) 421-428.

[64] A. Schluter, S. Fourcade, E. Domenech-Estevez, T. Gabaldon, J. Huerta-Cepas, G. Berthommier, R. Ripp, R.J. Wanders, O. Poch, A. Pujol, Peroxisome-DB: a database for the peroxisomal proteome, functional genomics and disease, Nucleic Acids Res. 35 (2007) D815-D822.

[65] S. Wiese, T. Gronemeyer, R. Ofman, M. Kunze, C.P. Grou, J.A. Almeida, M. Eisenacher, C. Stephan, H. Hayen, L. Schollenberger, T. Korosec, H.R. Waterham, W. Schliebs, R. Erdmann, J. Berger, H.E. Meyer, W. Just, J.E. Azevedo, R.J. Wanders, B. Warscheid, Proteomics characterization of mouse kidney peroxisomes by tandem mass spectrometry and protein correlation profiling, Mol. Cell. Proteomics 6 (2007) 2045-2057.

[66] B.K. Zolman, M. Monroe-Augustus, I.D. Silva, B. Bartel, Identification and functional characterization of Arabidopsis PEROXIN 4 and the interacting protein PEROXIN22, Plant Cell 17 (2005) 3422-3435. 
[67] C.S. Collins, J.E. Kalish, J.C. Morrell, J.M. McCaffery, S.J. Gould, The peroxisome biogenesis factors Pex4p, Pex22p, Pex1p, and Pex6p act in the terminal steps of peroxisomal matrix protein import, Mol. Cell. Biol. 20 (2000) 7516-7526.

[68] T. Gabaldon, B. Snel, F. van Zimmeren, W. Hemrika, H. Tabak, M.A. Huynen, Origin and evolution of the peroxisomal proteome, Biol. Direct 1 (2006) 8.

[69] A. Schluter, S. Fourcade, R. Ripp, J.L. Mandel, O. Poch, A. Pujol, The evolutionary origin of peroxisomes: an ER-peroxisome connection, Mol. Biol. Evol. 23 (2006) 838-845.

[70] A.F. Carvalho, C.P. Grou, M.P. Pinto, I.S. Alencastre, J. Costa-Rodrigues, M. Fransen, C. SaMiranda, J.E. Azevedo, Functional characterization of two missense mutations in Pex5peC $11 S$ and N526K, Biochim. Biophys. Acta 1773 (2007) 1141-1148.

[71] S. Leon, S. Subramani, A conserved cysteine residue of Pichia pastoris Pexzop is essential for its recycling from the peroxisome to the cytosol, J. Biol. Chem. 282 (2007) 7424-7430.

[72] A. Hensel, S. Beck, F. El Magraoui, H.W. Platta, W. Girzalsky, R. Erdmann, Cysteine-dependent ubiquitination of Pex18p is linked to cargo translocation across the peroxisomal membrane, J. Biol. Chem. 286 (2011) 43495-43505.

[73] X. Liu, S. Subramani, Unique requirements for mono- and polyubiquitination of the peroxisomal targeting signal co-receptor, Pex20, J. Biol. Chem. 288 (2013) 7230-7240.

[74] C.P. Grou, A.F. Carvalho, M.P. Pinto, S. Wiese, H. Piechura, H.E. Meyer, B. Warscheid, C. SaMiranda, J.E. Azevedo, Members of the $\mathrm{E}_{2} \mathrm{D}\left(\mathrm{UbCH}_{5}\right)$ family mediate the ubiquitination of the conserved cysteine of Pex5p, the peroxisomal import receptor, J. Biol. Chem. 283 (2008) 1419014197.

[75] M. Sichting, A. Schell-Steven, H. Prokisch, R. Erdmann, H. Rottensteiner, Pex7p and Pex2op of Neurospora crassa function together in PTS2-dependent protein import into peroxisomes, Mol. Biol. Cell 14 (2003) 810e821.

[76] H. Gonen, B. Bercovich, A. Orian, A. Carrano, C. Takizawa, K. Yamanaka, M. Pagano, K. Iwai, A. Ciechanover, Identification of the ubiquitin carrier proteins, E2s, involved in signal-induced conjugation and subsequent degradation of IkappaBalpha, J. Biol. Chem. 274 (1999) 14823-14830.

[77] M.K. Saville, A. Sparks, D.P. Xirodimas, J. Wardrop, L.F. Stevenson, J.C. Bourdon, Y.L. Woods, D.P. Lane, Regulation of $\mathrm{p}_{53}$ by the ubiquitin-conjugating enzymes $\mathrm{UbCH}_{5} \mathrm{~B} / \mathrm{C}$ in vivo, J. Biol. Chem. 279 (2004) 42169-42181.

[78] G. Koellensperger, S. Daubert, R. Erdmann, S. Hann, H. Rottensteiner, Characterisation of zincbinding domains of peroxisomal RING finger proteins using size exclusion chromatography/inductively coupled plasma-mass spectrometry, Biol. Chem. 388 (2007) 12091214 . 
[79] C. Williams, M. van den Berg, E. Geers, B. Distel, Pex1op functions as an E3 ligase for the Ubc4p-dependent ubiquitination of Pex5p, Biochem. Biophys. Res. Commun. 374 (2008) 620-624.

[8o] N. Kaur, Q. Zhao, Q. Xie, J. Hu, Arabidopsis RING peroxins are E3 ubiquitin ligases that interact with two homologous ubiquitin receptor proteins(F), J. Integr. Plant Biol. 55 (2013) 108-120.

[81] H.W. Platta, F. El Magraoui, B.E. Baumer, D. Schlee, W. Girzalsky, R. Erdmann, Pex2 and pex12 function as protein-ubiquitin ligases in peroxisomal protein import, Mol. Cell. Biol. 29 (2009) 55055516.

[82] C.C. Chang, D.S. Warren, K.A. Sacksteder, S.J. Gould, PEX12 interacts with PEX 5 and PEX10 and acts downstream of receptor docking in peroxisomal matrix protein import, J. Cell Biol. 147 (1999) $761-774$.

[83] P.P. Hazra, I. Suriapranata, W.B. Snyder, S. Subramani, Peroxisome remnants in pexzdelta cells and the requirement of Pexзp for interactions between the peroxisomal docking and translocation subcomplexes, Traffic 3 (2002) 560-574.

[84] L. Zhang, S. Leon, S. Subramani, Two independent pathways traffic the intraperoxisomal peroxin PpPex8p into peroxisomes: mechanism and evolutionary implications, Mol. Biol. Cell 17 (2006) 690-699.

[85] D.M. Wenzel, R.E. Klevit, Following Ariadne's thread: a new perspective on RBR ubiquitin ligases, BMC Biol. 10 (2012) 24.

[86] J. Hu, A. Baker, B. Bartel, N. Linka, R.T. Mullen, S. Reumann, B.K. Zolman, Plant peroxisomes: biogenesis and function, Plant Cell 24 (2012) 2279-2303.

[87] X. Liu, C. Ma, S. Subramani, Recent advances in peroxisomal matrix protein import, Curr. Opin. Cell Biol. 24 (2012) 484-489.

[88] H.W. Platta, S. Hagen, R. Erdmann, The exportomer: the peroxisomal receptor export machinery, Cell. Mol. Life Sci. 70 (2013) 1393-1411.

[89] N. Miyata, K. Okumoto, S. Mukai, M. Noguchi, Y. Fujiki, AWP1/ZFAND6 functions in Pex5 export by interacting with cys-monoubiquitinated Pex5 and Pex6 AAA ATPase, Traffic 13 (2012) 168-183.

[9o] W. Duan, B. Sun, T.W. Li, B.J. Tan, M.K. Lee, T.S. Teo, Cloning and characterization of AWP1, a novel protein that associates with serine/threonine kinase PRK1 in vivo, Gene 256 (2000) 113-121.

[91] E.J. Chang, J. Ha, S.S. Kang, Z.H. Lee, H.H. Kim, AWP1 binds to tumor necrosis factor receptorassociated factor 2 (TRAF2) and is involved in TRAF2-mediated nuclear factor-kappaB signaling, Int. J. Biochem. Cell Biol. 43 (2011) 1612-1620.

[92] B.J. Fenner, M. Scannell, J.H. Prehn, Identification of polyubiquitin binding proteins involved in NF-kappaB signaling using protein arrays, Biochim. Biophys. Acta 1794 (2009) 1010-1016. 
[93] K. Okumoto, S. Misono, N. Miyata, Y. Matsumoto, S. Mukai, Y. Fujiki, Cysteine ubiquitination of PTS1 receptor Pex5p regulates Pex5p recycling, Traffic 12 (2011) 1067-1083.

[94] M.B. Metzger, V.A. Hristova, A.M. Weissman, HECT and RING finger families of E3 ubiquitin ligases at a glance, J. Cell Sci. 125 (2012) 531-537.

[95] M. Fransen, M. Nordgren, B. Wang, O. Apanasets, Role of peroxisomes in ROS/ RNSmetabolism: implications for human disease, Biochim. Biophys. Acta 1822 (2012) 1363-1373.

[96] B. Huhse, P. Rehling, M. Albertini, L. Blank, K. Meller, W.H. Kunau, Pex17p of Saccharomyces cerevisiae is a novel peroxin and component of the peroxisomal protein translocation machinery, $J$. Cell Biol. 140 (1998) 49-6o.

[97] L. Opalinski, J.A. Kiel, T.G. Homan, M. Veenhuis, I.J. van der Klei, Penicillium chrysogenum Pex14/17p e a novel component of the peroxisomal membrane that is important for penicillin production, FEBS J. 277 (2010) 3203-3218.

[98] D. Managadze, C. Wurtz, S. Wiese, M. Schneider, W. Girzalsky, H.E. Meyer, R. Erdmann, B. Warscheid, H. Rottensteiner, Identification of PEX33, a novel component of the peroxisomal docking complex in the filamentous fungus Neurospora crassa, Eur. J. Cell Biol. 89 (2010) 955-964. 
Table 1: The Peroxisomal Import Machinery (PIM). Peroxisomal protein import components are organized into functional/structural units. Their subcellular localization and key features, as well as their distribution among different organisms are indicated. $\mathrm{M}$, mammals; $\mathrm{P}$, plants; $\mathrm{Y}$, yeast; $\mathrm{F}$, fungi; IDD, intrinsically disordered domain; TPRs, tetratricopeptide repeats; $\mathrm{SH}_{3}$, Src homology 3 domain; RING, really interesting new gene; $A A A, A T P a s e s$ associated with diverse cellular activities. \# PEX1.PEX6-membrane anchor: PEX26 (M, Y, F), APEM9 (P), or PEX15 (Y). PEX8 [30]; PEX17 [96]; PEX14/17 [97]; PEX33 [98].

\begin{tabular}{|c|c|c|c|}
\hline \multicolumn{3}{|c|}{ PIM Components } & \multirow{2}{*}{$\begin{array}{l}\text { Properties } \\
\text { Cytosolic/Peroxisomal; } \\
\text { IDD/TPRs; PTS1 sorting }\end{array}$} \\
\hline $\begin{array}{l}\text { Shuttling } \\
\text { Receptors }\end{array}$ & $\begin{array}{l}\text { PEX5 } \\
\text { PEX5.PEX7 } \\
\text { (PEX18/PEX21).PEX7 } \\
\text { PEX20.PEX7 }\end{array}$ & $\begin{array}{l}\text { M, P, Y, F } \\
\text { M, P } \\
\text { Y } \\
\text { Y, F }\end{array}$ & \\
\hline $\begin{array}{l}\text { Docking } \\
\text { Translocation } \\
\text { Module } \\
\text { (DTM) }\end{array}$ & $\begin{array}{l}\text { PEX14 } \\
\text { PEX13 } \\
\text { PEX17 } \\
\text { PEX14/17(PEX33) } \\
\text { PEX8 } \\
\text { PEX2 } \\
\text { PEX10 } \\
\text { PEX12 }\end{array}$ & $\begin{array}{l}M, P, Y, F \\
M, P, Y, F \\
Y \\
F \\
Y, F \\
M, P, Y, F \\
M, P, Y, F \\
M, P, Y, F\end{array}$ & $\begin{array}{l}\text { Peroxisomal; coiled-coil } \\
\text { Peroxisomal; SH3 } \\
\text { Peroxisomal; coiled-coil } \\
\text { Peroxisomal; coiled-coil } \\
\text { Peroxisomal }\end{array}$ \\
\hline $\begin{array}{l}\text { Receptor Export } \\
\text { Module } \\
\text { (REM) }\end{array}$ & $\begin{array}{l}\text { PEX1.PEX6.anchor } \\
\text { AWP1 }\end{array}$ & $\begin{array}{l}M, P, Y, F \\
M\end{array}$ & $\begin{array}{l}\text { Peroxisomal; AAA ATPase } \\
\text { Cytosolic; adaptor protein; } \\
\text { A20 and AN1 zinc finger domains }\end{array}$ \\
\hline $\begin{array}{l}\text { Ubiquitin- } \\
\text { conjugating } \\
\text { enzymes }\end{array}$ & $\begin{array}{l}\text { E2D1/2/3 } \\
\text { PEX4.PEX22 }\end{array}$ & $\begin{array}{l}\mathbf{M} \\
\mathbf{P}, \mathbf{Y}, \mathbf{F}\end{array}$ & $\begin{array}{l}\text { Cytosolic; E2 } \\
\text { Peroxisomal; E2 }\end{array}$ \\
\hline $\begin{array}{l}\text { Deubiquitinating } \\
\text { enzymes } \\
\text { (DUBs) }\end{array}$ & $\begin{array}{l}\text { USP9X } \\
\text { UBP15 }\end{array}$ & $\begin{array}{l}\mathbf{M} \\
\mathbf{Y}\end{array}$ & $\begin{array}{l}\text { Cytosolic } \\
\text { Partially Peroxisomal }\end{array}$ \\
\hline
\end{tabular}




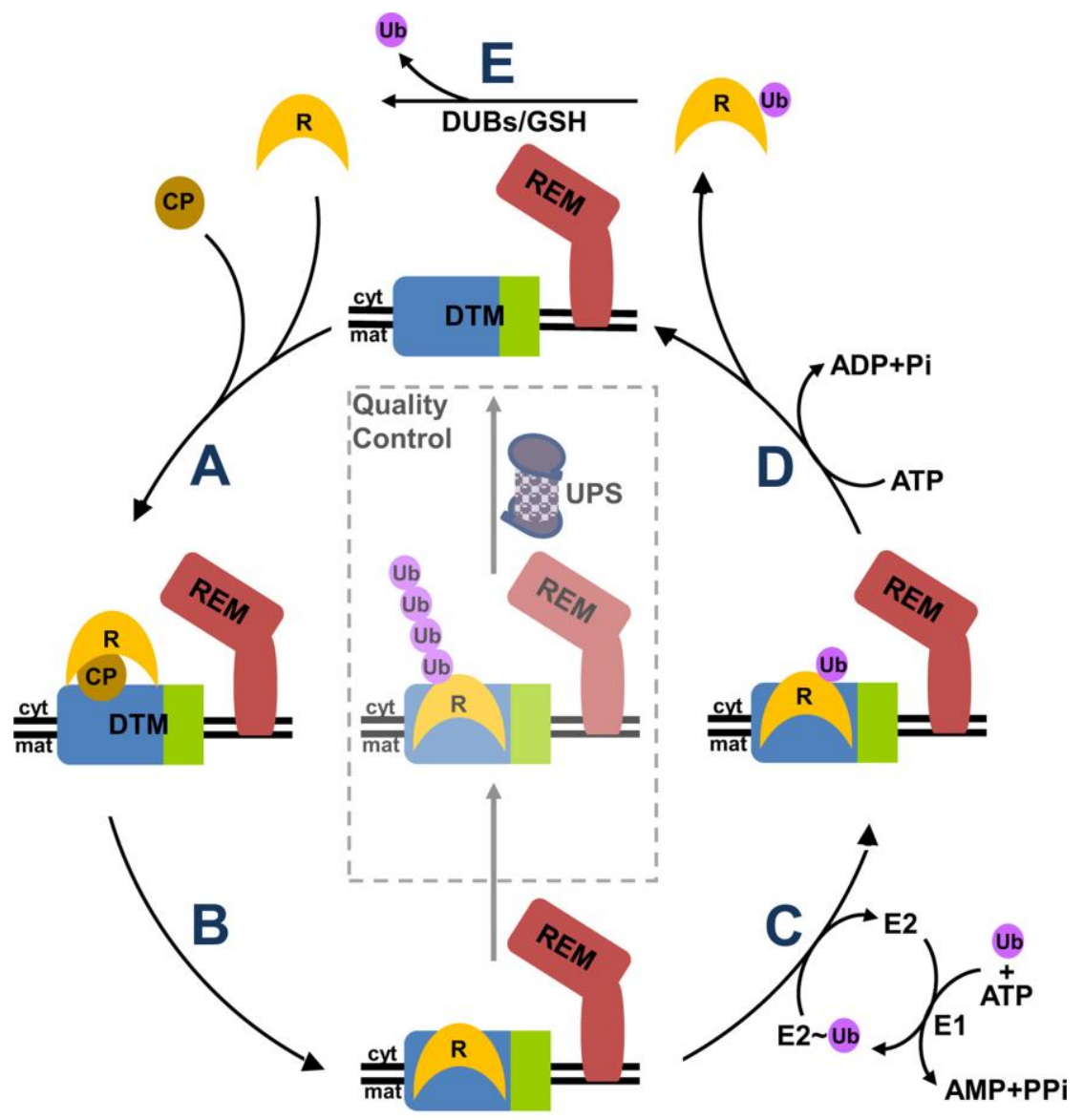

CP

Fig. 1. The roles of ubiquitin in the peroxisome protein import machinery. Peroxisomal matrix cargo proteins (CP) are recognized by cycling receptors (R) in the cytosol. These receptor-cargo protein complexes dock at the peroxisomal membrane docking/translocation module (DTM) (arrow A). The strong protein-protein interactions established between the receptor and DTM components result in the insertion of the receptor into the DTM with the concomitant translocation and release of the cargo protein into the organelle matrix (arrow B). The receptor is then monoubiquitinated at a conserved cysteine residue (arrow C), and extracted back to the cytosol by the ATP-dependent receptor export module (REM) (arrow D). Finally, the ubiquitin moiety is removed probably by a combination of enzymatic (DUBs) and non-enzymatic mechanisms (e.g., by nucleophiles such as glutathione, GSH) (arrow E). When receptors become jammed at the DTM, they are removed and degraded via the ubiquitin-proteasome pathway (UPS). 